\title{
PENGARUH INTENSITAS RADIASI MATAHARI TERHADAP PERTUMBUHAN DAN KUALITAS SELADA MERAH (Lactuca sativa L.)
}

\section{EFFECT INTENSITY OF SOLAR RADIATION ON THE GROWTH AND QUALITY OF RED LETTUCE (Lactuca sativa L.)}

\author{
Mila Mil'atu Rohmah, Paul Benyamin Timotiwu, Tumiar Katarina B. Manik, \\ Yohannes Cahya Ginting
}

\author{
Jurusan Agroteknologi, Fakultas Pertanian, Universitas Lampung \\ Jl Sumantri Brojonegoro 1, Bandar Lampung 35145, Indonesia \\ *Email:r.milamilatu@gmail.com
}

\begin{abstract}
Red lettuce growing demand by the public because it has a crunchy texture and attractive color. This study aims to determine the effectiveness of $U V$ plastic shade in reducing the intensity of solar radiation, know the growth and quality of red lettuce under plastic shade UV filters as an alternative to the development of red lettuce in the lowlands. The research was conducted on Teluk Betung, Bandar Lampung with treatment without hood and treatment using UV filters plastic shade 14\%-shaped tunnel, each treatment had 30 samples. Data obtained in a test using t-test analysis a level of 5\%. The results showed that the average plastic used effectively lower UV radiation intensity of 641 watts. $m E^{2}$ to 464 watts. $m E^{2}$ (38\%), the temperature during the day outside and inside the shade that is $37 \overline{U C}$ and $36 \overline{U C}$, and humidity outside and inside the shade only 49\% and 50\%. The treatment without shade produced a greater number of leaves than those in the shade, and the fresh weight of the plants better in treatment without the shade by $35 \%$. Display color red lettuce visually better on treatment without plastic shade 14\% UV filter that produces lettuce plants with the dominant red color.
\end{abstract}

Keywords: Intensity of solar radiation, humidity, red lettuce, UV plastic shade, temperature.

\begin{abstract}
ABSTRAK
Selada merah semakin diminati oleh masyarakat karena memiliki tekstur yang renyah dan warna yang menarik. Penelitian ini bertujuan untuk mengetahui efektifitas naungan plastik UV dalam mengurangi intensitas radiasi matahari, mengetahui pertumbuhan dan kualitas selada merah di bawah naungan plastik penyaring UV sebagai suatu alternatif pengembangan selada merah di dataran rendah. Penelitian dilaksanakan di Teluk Betung, Bandar Lampung dengan perlakuan tanpa naungan dan perlakuan menggunakan naungan plastik penyaring UV $14 \%$ berbentuk terowongan, masing-masing perlakuan memiliki 30 sampel. Data yang diperoleh di uji menggunakan analisis Uji-t taraf $\alpha$ 5\%. Hasil penelitian menunjukkan bahwa rata-rata plastik UV yang digunakan efektif menurunkan intensitas radiasi dari 641 watts. $\mathrm{mE}^{2}$ menjadi 464 watts.mÉ ${ }^{2}(38 \%)$, suhu pada siang hari di luar dan di dalam naunganyaitu 37ÚC dan 36ÚC, dan kelembaban udara di luar dan di dalam naungan hanya 49\% dan $50 \%$. Perlakuan tanpa naungan menghasilkan jumlah daun yang lebih banyak daripada yang di dalam naungan, dan bobot segar tanaman lebih baik pada perlakuan tanpa naungan sebesar 35\%. Tampilan warna selada merah
\end{abstract}


secara visual lebih baik pada perlakuan tanpa sungkup plastik penyaring UV 14\% yang menghasilkan tanaman selada dengan warna merah yang dominan.

Kata kunci: Intensitas radiasi matahari, Kelembaban Udara, Naungan plastik UV, Selada merah, Suhu Udara.

\section{PENDAHULUAN}

Selada dalam beberapa negara dijadikan sebagai sayuran utama untuk bahan salad. Selada merah (Lactuca sativa L.) adalah jenis leaf lettuce yang memiliki daun berwarna merah, lebar, tipis, serta bergerombol dan tampak keriting. Dalam budidaya tanaman hortikultura faktor lingkungan tumbuh harus diperhatikan agar hasil panennya memuaskan. Lingkungan tumbuh tanaman identik dengan faktor luar atau faktor di sekitar tanaman. Beberapa faktor luar yang penting dalam menentukan pertumbuhan dan produksi tanaman diantaranya adalah tanah, nutrisi, air, sinar matahari, dan suhu udara (Ashari, 2006). Selada tumbuh dengan baik di dataran tinggi dengan suhu sekitar $15-20^{\circ} \mathrm{C}$. Tanaman ini dapat dibudidayakan di dataran rendah, namun akan menghasilkan daun selada/krop yang kecil dan tanaman akan cepat berbunga (Novitasari, 2018).Selada merah semakin diminati oleh masyarakat karena memiliki tekstur yang renyah dan warna yang menarik. Untuk budidaya selada merah di dataran rendah perlu diterapkan teknik naungan untuk mengurangi intensitas radiasi matahari yang diharapkan dapat menurunkan suhu, sehingga dapat sesuai dengan suhu optimum tanaman. Pada kondisi suhu optimum, laju pertumbuhan tanaman akan berjalan pada kecepatan maksimum apabila faktorfaktor lain tidak menjadi pembatas. Dalam hal ini dipilih penggunaan plastik penyaring UV karena selain mengurangi intensitas radiasi matahari lalu menurunkan suhu, diharapkan plastik ini juga menyaring sinar UV yang mungkin tidak dibutuhkan oleh tanaman. Tujuan penelitian ini adalah untuk mengetahui efektifitas naungan plastik UV dalam mengurangi intensitas radiasi matahari, mengetahui pertumbuhan dan kualitas selada merah di bawah naungan plastik penyaring UV sebagai suatu alternatif pengembangan selada merah di dataran rendah.

\section{BAHAN DAN METODE}

Penelitian ini dilaksanakan di Kelurahan Gulak Galik, Teluk Betung Utara, Bandar Lampung pada bulan Mei sampai dengan Juni 2019. Terdapat dua perlakuan, yaitu kontrol tanpa naungan, dan perlakuan menggunakan naungan plastik UV 14\% berbentuk terowongan, masing-masing perlakuan memiliki 30 sampel polybag yang diletakkan berjejer dengan jarak $10 \mathrm{~cm}$ antar polybag agar kanopi tanaman tidak saling menutupi. Naungan yang digunakan memiliki tinggi 2 $\mathrm{m}$, lebar 1,5 m, dan panjang $2 \mathrm{~m}$ (Gambar 1). Bahanbahan yang digunakan adalah benih selada merah varietas Lollo rossa, tanah top soil, kascing 120 g, pupuk dasar NPK 3 g. Sedangkan alat yang digunakan yaitu bambu, kawat kecil, plastik penyaring UV 14\%, polybag $3 \mathrm{~kg}$, parang, alat tulis, cangkul, ember, kamera, timbangan digital, label sampel, meteran, penggaris, pyranometer, selang air, dan thermo 


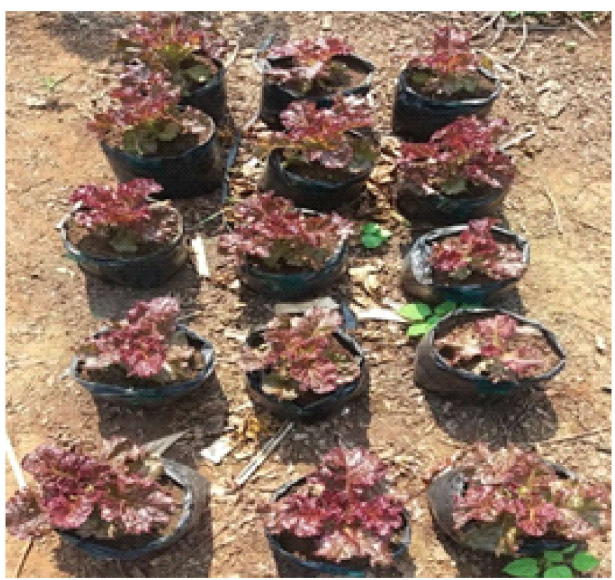

(a)

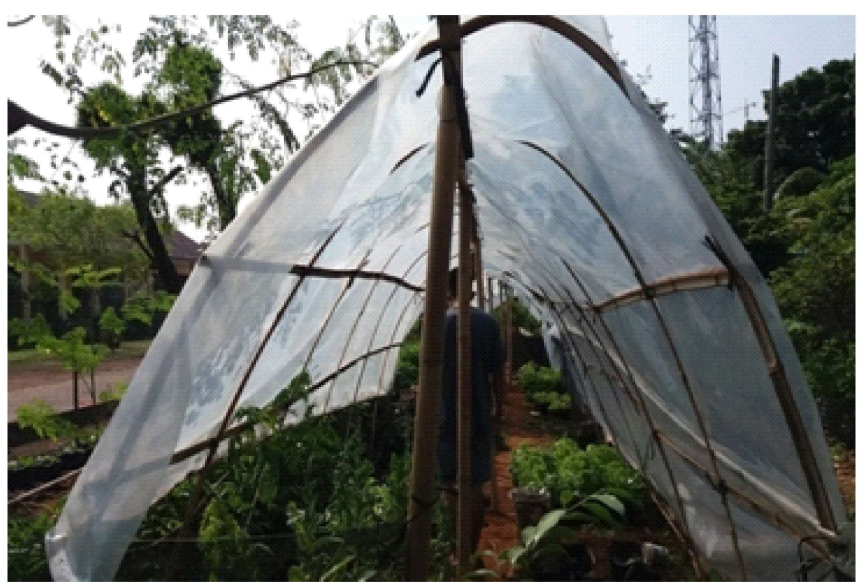

(b)

Gambar 1. Perlakuan kontrol tanpa naungan (a), perlakuan menggunakan naungan plastik UV 14\% (b).

hygrometer. Dilakukan pengukuran intensitas radiasi matahari, suhu, dan kelembaban di dalam dan di luar naungan, hasilnya di tampilkan dalam bentuk grafik. Data hasil pengamatan pertumbuhan selada merah, meliputi panjang batang, jumlah daun, panjang daun, lebar daun, bobot segar tanaman, dan bobot kering akar diuji menggunakan analisis Uji-t taraf $\alpha$ 5\%.

\section{HASIL DAN PEMBAHASAN}

Hasil pengukuran intensitas cahaya dapat dilihat pada Gambar 2. Pengukuran dilakukan siang hari pukul 12.00-13.00 wib selama 4 MST. Sedangkan perbedaan intensitas cahaya matahari pagi, siang, dan sore ditampilkan dalam Gambar 3.Naungan plastik UV yang digunakan efektifmenurunkan intensitas radiasi matahari, rata-rata intensitas radiasi matahari yang masuk kedalam naungan khususnya pada pagi sebesar $38 \%$, siang hari sebesar $38 \%$, dan sore hari sebesar 28\%. Secara rata-rata plastik UV yang digunakan menurunkan intensitas radiasi dari 641 watts.mÉ ${ }^{2}$ menjadi 464 watts.mÉ ${ }^{2}$ (38\%).
Sebagai akibat dari pengurangan intensitas radiasi oleh naungan, diharapkan terjadi perubahan suhu dan kelembaban di luar dan di dalam naungan. Hasil pengukuran suhu udara dapat dilihat pada Gambar 4. Naungan plastik yang digunakan ternyata tidak secara konsisten menurunkan suhu didalam naungan, rata-rata suhu pada siang hari didalam dan diluar naungan hampir sama yaitu $37^{\circ} \mathrm{C}$ dan $36^{\circ} \mathrm{C}$. Perbedaan suhu udara pagi, siang, dan sore di dalam naungan dan diluar naungan dapat dilihat pada Gambar 5. Suhu di bawah naungan plastik UV tetap tinggi, pada pagi dan sore hari suhu kontrol dengan suhu dalamnaunganhampir sama, hanya pada siang hari terdapat perbedaan terutama pada saat suhu sangat tinggi. Pengukuran suhu dilakukan dengan ketinggian $50 \mathrm{~cm}$ diatas permukaan tanah. Meningkatnya suhu udara di dalam naungan disebabkan oleh radiasi gelombang panjang yang terperangkap di dalam naungan. Radiasi gelombang pendek yang masuk kedalam naungan diubah menjadi gelombang panjang karena melewati bahan penutup, yaitu atap dan dinding sungkup, serta dipancarkan oleh 


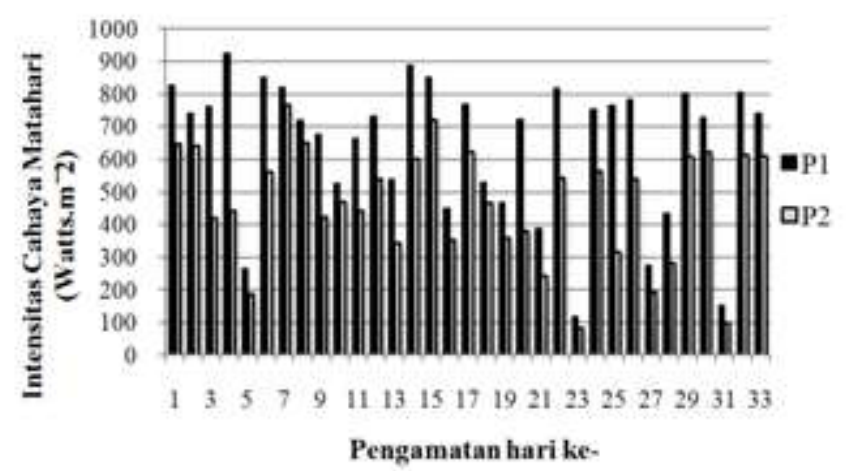

Gambar 2. Grafik hasil pengukuran intensitas cahaya matahari, suhu, dan kelembaban. Perlakuan kontrol (P1), perlakuan naungan plastik UV 14\% (P2).

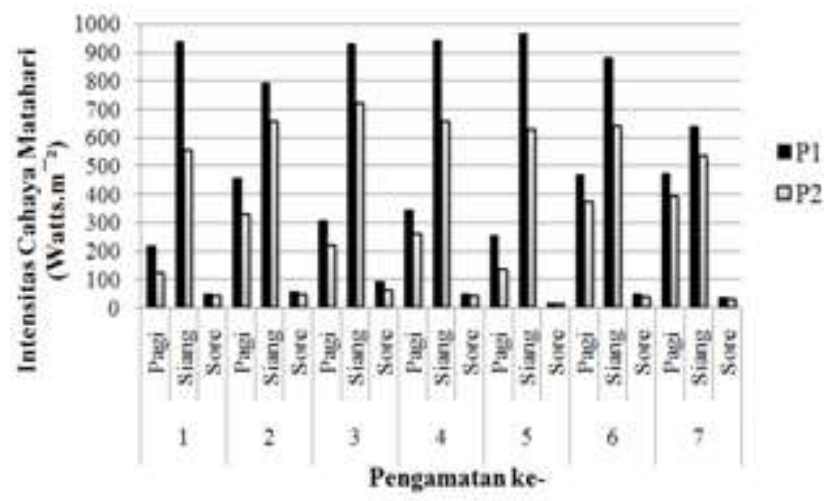

Gambar 3. Grafik perbedaan hasil pengukuran intensitas cahaya matahari pagi, siang, dan sore hari. Perlakuan kontrol (P1), perlakuan naunganplastik UV 14\%(P2).

lantai maupun bagian konstruksi naungan. Selain itu, naiknya suhu pada naungan dapat juga disebabkan oleh lebih intensifnya gelombang panjang yang dipancarkan kedalam naungan (Suhardiyanto, 2009). Meskipun naungan tidak sepenuhnya tertutup, tetapi karena naungan rendah dengan ketinggian $200 \mathrm{~cm}$ maka angin tidak dapat memindahkan energi panas yang berada di dalam naungan.

Hasil pengukuran kelembaban udara dapat dilihat pada Gambar 6. Dalam beberapa pengukuran kelembaban udara didalam naungan lebih tinggi daripada diluar naungan, tetapi tidak konsisten. Ratarata kelembaban diluar dan didalam naungan berkisar

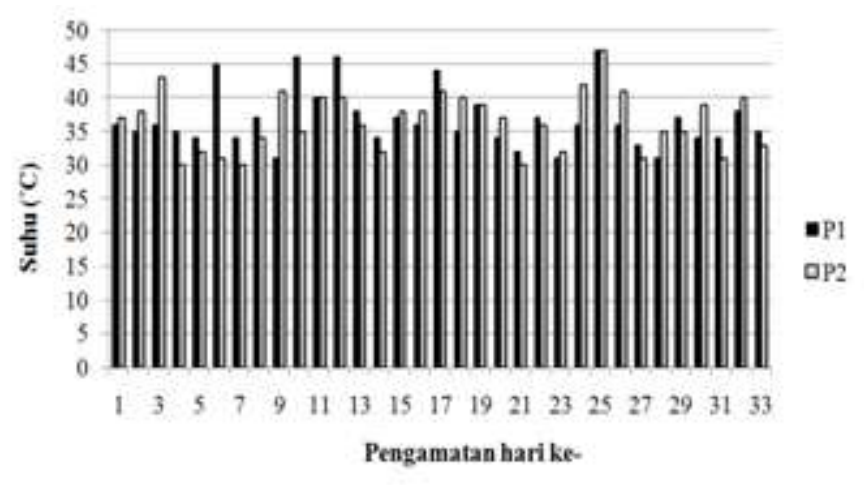

Gambar 4. Grafik hasil pengukuran suhu udara. Perlakuan kontrol(P1), perlakuan naungan plastik UV 14\%(P2).

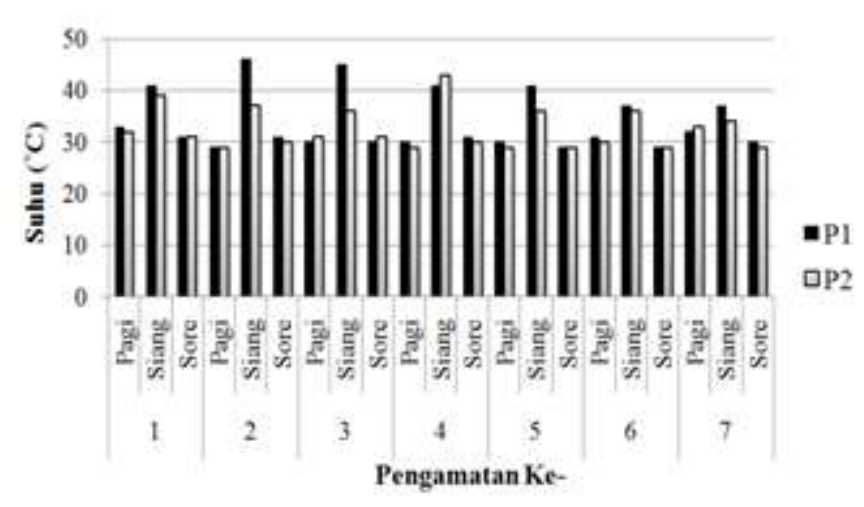

Gambar 5. Grafik perbedaan hasil pengukuran suhu udara pagi, siang, dan sore hari. Perlakuan kontrol (P1), perlakuan naunganplastik UV 14\% (P2).

$49 \%$ dan $50 \%$ yang berarti udara cukup kering. Perbedaan kelembaban pagi, siang, dan sore hari dapat dilihat pada Gambar 7. Secara umum tidak ada perbedaan yang konsisten antara kelembaban udara diluar dan didalam naungan pada pagi, siang, dan sore hari. Suhu yang tinggi didalam naungan seharusnya mengakibatkan laju evaporasi meningkat, dan kelembaban juga meningkat, tetapi jika tanah telah berada dalam keadaan kering maka tidak ada lagi kelembaban yang diuapkan, sehingga udara menjadi kering (kelembaban rendah).

Untuk melihat hubungan antara suhu dan kelembaban, maka data suhu dan kelembaban disajikan 


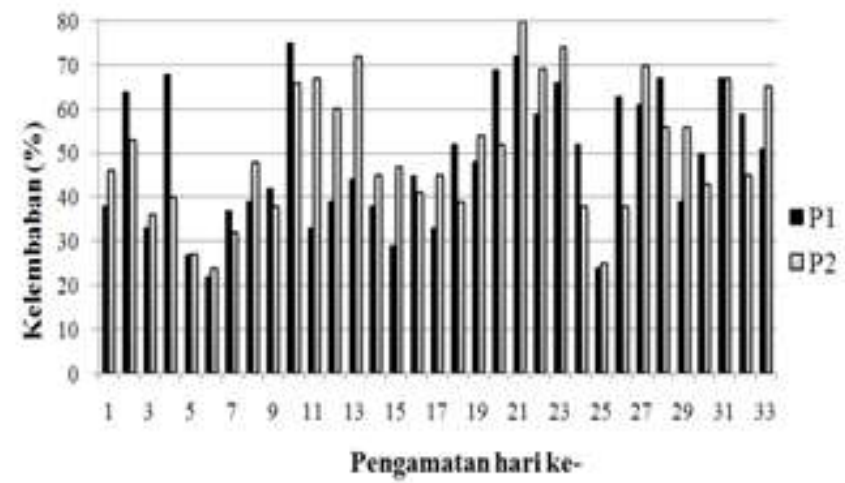

Gambar 6. Grafik hasil pengukuran kelembaban udara. Perlakuan kontrol (P1), perlakuannaungan plastik UV 14\%(P2).

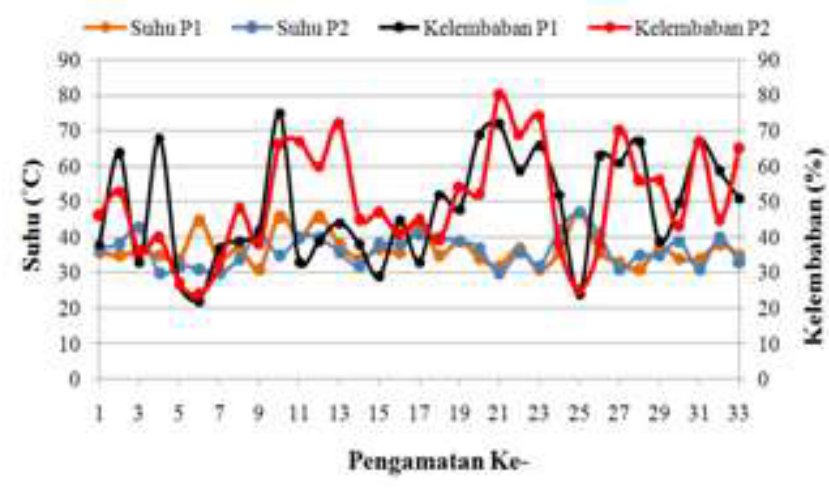

Gambar 8. Grafik hubungan antara suhu dan kelembaban di dalam dan diluar naungan.Perlakuan kontrol (P1), perlakuan naungan plastik UV 14\% (P2).

bersama dan hasilnya dapat dilihat pada Gambar 8 . Hasil pengukuran menunjukkan pola yang berbanding terbalik antara suhu dan kelembaban udara, saat suhu tinggi maka kelembaban rendah; yang menunjukkan tidak cukup banyak uap air yang menempati kapasitas udara dalam menampung uap air. Akan tetapi, dalam beberapa pengukuran baik di dalam maupun di luar naungan menghasilkan pola suhu dan kelembaban yang hampir sama. Sebuah penelitian untuk mengetahui pengaruh penggunaan paranet terhadap iklim mikro tanaman tembakau menunjukkan bahwa tidak semua pengukuran menghasilkan nilai suhu yang berbanding terbalik dengan nilai kelembaban udara (Sudaryono,

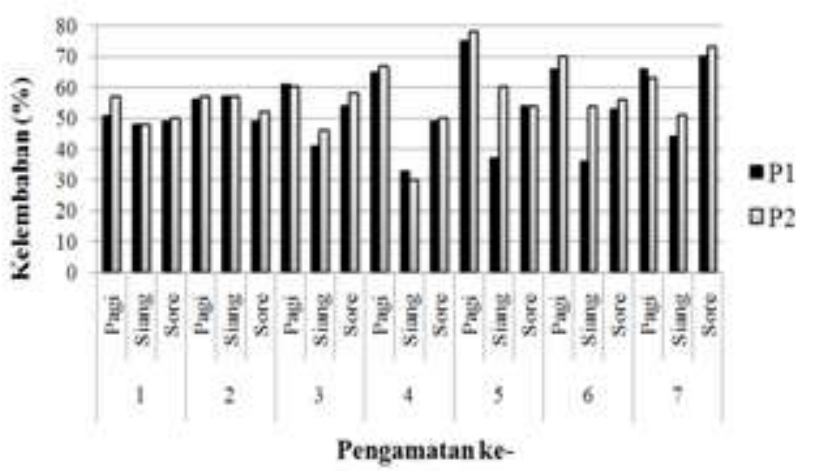

Gambar 7. Grafik perbedaan hasil pengukuran kelembaban udara pagi, siang, dan sore hari.Perlakuan kontrol (P1), perlakuan naunganplastik UV 14\% (P2).

2004). Jika pola suhu berimpit dengan pola kelembaban, maka itu berarti air di permukaan tanah cukup untuk memenuhi laju evaporasi. Kelembaban yang rendah menunjukkan permukaan tanah dalam naungan kering.

Pengukuran untuk variabel pertumbuhan tanaman selada merah dapat dilihat pada Tabel 1.Hasil uji-t (Tabel 1) menunjukkan bahwa adanya perbedaan pengaruh perlakuan terhadap jumlah daun dan bobot segar tanaman. Tabel 1 menunjukkanadanya perbedaan pengaruh perlakuan terhadap jumlah daun dan bobot segar tanaman antara perlakuan kontrol dengan perlakuan naungan plastik penyaring UV 14\%. Pemberian naungan plastik memberikan pengaruh yang sangat berbeda nyata terhadap jumlah daun, dan memberikan pengaruh yang berbeda nyata terhadap bobot segar tanaman selada merah. Baik jumlah daun maupun bobot segar tanaman lebih rendah pada penanaman dibawah naungan dibandingkan di luar naungan. Tingginya suhu udara berpengaruh tidak baik terhadap jumlah daun dan akhirnya bobot segar tanaman menjadi berkurang.Purnono dkk (2018) menyatakan bahwa suhu yang tinggi akan 


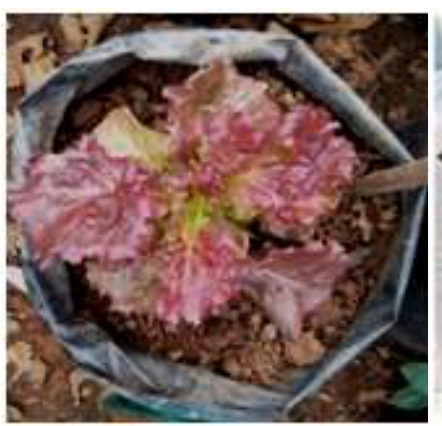

(a)

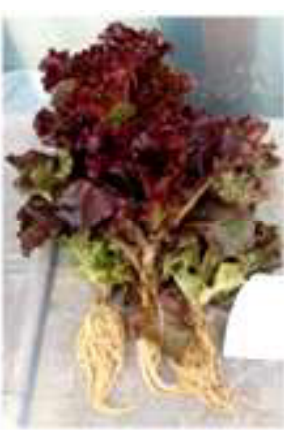

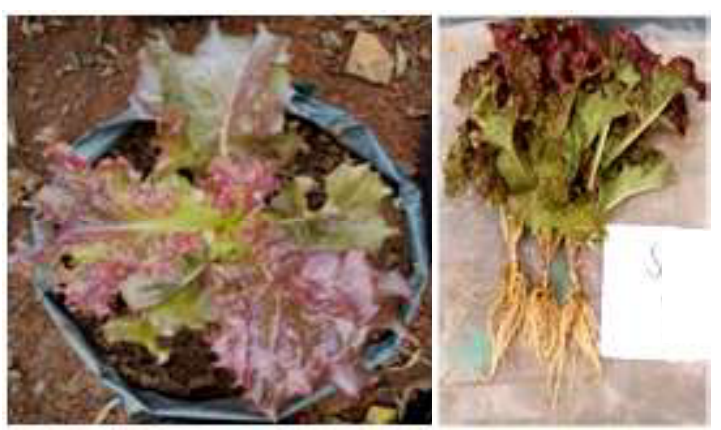

(b)

Gambar 9. Pengaruh pengurangan intensitas radiasi matahari terhadap kualitas warna daun selada merah. Kualitas warna daun perlakuan kontrol (A), kualitas warna daun perlakuan naungan plastik UV 14\% (B).

Tabel 1. Hasil Uji-t pengaruh pengurangan intensitas radiasi matahari terhadap pertumbuhan tanaman selada merah

\begin{tabular}{|c|c|c|c|c|c|}
\hline Variabel & Perlakuan & Nilai tengah & P value & t-hitung & t-tabel \\
\hline Panjang batang $(\mathrm{cm})$ & $\begin{array}{c}\text { Kontrol } \\
\text { Naungan }\end{array}$ & $\begin{array}{l}11,64 \\
11,44\end{array}$ & $0,4477 \mathrm{tn}$ & 0,13 & 1,67 \\
\hline Jumlah daun (helai) & $\begin{array}{l}\text { Kontrol } \\
\text { Naungan }\end{array}$ & $\begin{array}{c}13,97 \\
10,5\end{array}$ & $0,0000005^{* *}$ & 5,44 & 1,67 \\
\hline Panjang daun $(\mathrm{cm})$ & $\begin{array}{l}\text { Kontrol } \\
\text { Naungan }\end{array}$ & $\begin{array}{l}12,31 \\
12,62\end{array}$ & $0,2151 \mathrm{tn}$ & 0,79 & 1,67 \\
\hline Lebar daun $(\mathrm{cm})$ & $\begin{array}{l}\text { Kontrol } \\
\text { Naungan }\end{array}$ & $\begin{array}{l}10,09 \\
10,13\end{array}$ & $0,4571 \mathrm{tn}$ & 0,10 & 1,68 \\
\hline Bobot segar tanaman $(\mathrm{g})$ & $\begin{array}{l}\text { Kontrol } \\
\text { Naungan }\end{array}$ & $\begin{array}{l}47,61 \\
35,25\end{array}$ & $0,0055^{*}$ & 2,62 & 1,67 \\
\hline Bobot kering akar (g) & $\begin{array}{l}\text { Kontrol } \\
\text { Naungan }\end{array}$ & $\begin{array}{l}0,55 \\
0,45\end{array}$ & $0,1486 \mathrm{tn}$ & 1,05 & 1,67 \\
\hline
\end{tabular}

mempengaruhi proses fotosintesis dan respirasi, apabila suhu terlalu panas maka respirasi tanaman akan semakin cepat dan tidak sebanding dengan fotosintesis sehingga fotosintat hasil fotosintesis akan terbagi untuk energi respirasi dan pembentukan umbi.

Pengamatan kualitas tanaman selada merah dilakukan secara visual dengan melihat perbedaan warna daun antar perlakuan (Gambar 9). Perlakuan kontrol menghasilkan daun dengan warna merah yang paling banyak daripada perlakuan naungan plastik penyaring UV 14\%. Perlakuan naungan plastik penyaring UV 14\% menunjukkan warna daun selada masih memiliki warna kehijauan.Tanaman dengan daun berwarna merah memiliki kandungan antosianin yang tinggi yang dapat berfungsi sebagai antioksidan yang mempengaruhi langsung kemampuan tanaman untuk beradaptasi terhadap lingkungan yang tidak sesuai. Khusni dkk (2018) melakukan penelitian tentang pengaruh naungan paranet terhadap pertumbuhan dan aktivitas antioksidan pada bayam merah melaporkan bahwa tanaman yang tidak ternaungi menghasilkan warna merah yang disebabkan karena perlakuan kontrol tanpa sungkup menghasilkan lebih banyak antosianin. Antosianin tersebut berfungsi melindungi kloroplas terhadap intensitas cahaya matahari yang tinggi dan menutupi klorofil sehingga warna merah mendominasi. 


\section{KESIMPULAN}

Berdasarkan penelitian yang telah dilakukan, dapat disimpulkan bahwa penggunaan naungan plastik penyaring UV 14\% efektif mengurangi intensitas radiasi matahari sebesar 38\%, namun tidak konsisten dalam menurunkan suhu (37ÚC) dan menaikkan kelembaban udara (50\%). Perlakuan tanpa naungan menghasilkan jumlah daun yang lebih banyak daripada di dalam naungan, dan bobot segar tanaman lebih baik pada perlakuan kontrol tanpa naungan sebesar 35\%. Tampilan warna selada merah secara visual lebih baik pada perlakuan tanpa naungan plastik penyaring UV 14\% yang menghasilkan tanaman selada dengan warna merah yang dominan.

\section{UCAPAN TERIMA KASIH}

Penulis mengucapkan terima kasih kepada pembimbing yang sudah membimbing penulis, dan semua pihak yang telah berkontribusi dalam penelitian ini, sehingga penelitian dapat terlaksana dengan baik.

\section{DAFTAR PUSTAKA}

Ashari, S. 2006. Hortikultura Aspek Budidaya. UI Press. Jakarta.

Khusni, L., Hastuti, B. R., dan Prihastanti, E. 2018. Pengaruh naungan terhadap pertumbuhan dan aktivitas antioksidan pada bayam merah (Alternanthera amoena Voss.). Buletin Anatomi dan Fisiologi. 3(1):1-9.

Novitasari, D. 2018. Respons pertumbuhan dan produksi selada (Lactuca sativa L.) terhadap perbedaan komposisi media tanam dan interval waktu aplikasi pupuk organik cair. Skripsi. Unila. Bandar Lampung.

Purnomo, D., Damanhuri., dan Winarno, W. 2018. Respon pertumbuhan dan hasil tanaman kentang (Solanum tuberosum L.) terhadap pemberian naungan dan pupuk kieserite di dataran medium. Agriprima. 2(1):67-68.

Sudaryono. 2004. Pengaruh naungan terhadap perubahan iklim mikro pada budidaya tanaman tembakau rakyat. J.Tek.Ling. 5(1):56-60.

Suhardiyanto, H. 2009. Teknologi Rumah Tanaman untuk Iklim Tropika Basah "Pemodelan dan Pengendalian Lingkungan”. IPB Press. Bogor. 